\title{
Mediaberichten, framing en hypes: over de relatie van media en criminaliteit en de analyse hiervan*
}

Martina Althoff

\section{Intro: criminaliteitsdiscoursen en mediamaatschappij}

De relatie tussen media en criminaliteit is een klassiek onderwerp van criminologisch onderzoek. Een centrale vraag is hoe criminaliteitsvraagstukken in het publieke debat worden besproken en welke betekenissen hieraan toegewezen worden. Hierop aansluitend is de vraag hoe de beeldvorming in de media de publieke opinie beïnvloedt en wat mogelijke effecten hiervan zijn. Een hiermee verbonden gedachte is dat de beeldvorming de beleving van de werkelijkheid van criminaliteit en straf bepalen.

Media staan niet los van de samenleving en het maatschappelijk discours. De tegenwoordige samenleving is als gemediatiseerd gekenmerkt en wordt ook dramademocratie $^{1}$ genoemd. Dat betekent dat criminaliteit, die altijd een grote nieuwswaarde had en met veel emoties verbonden wordt, tegenwoordig gecommodificeerd is en voor het amusement zorgt. Universele en permanente publieke aandacht is het gevolg.

\section{Beeldvorming en framing in de media}

De vraag naar de beeldvorming over criminaliteit en geweld in de media is cruciaal, omdat media definiëren wat en welke gebeurtenissen plaatsgevonden hebben in een samenleving. Media selecteren gebeurtenissen waarover ze gaan berichten en leveren interpretaties en verklaringen hoe deze gebeurtenissen te begrijpen zijn. (Media)criminologen hebben hier aansluiting gezocht bij het van de socioloog Erving Goffman ${ }^{2}$ ontwikkelde theoretisch concept van framing en de framinganalyse. Framing verwijst naar de wijze waarop een onderwerp wordt ingekaderd of belicht; het is iets wat media actief en expliciet doen. Sociale fenomenen worden als criminaliteits- en geweldsproblemen geframed. De framing is zo begrepen een interpretatiekader, omdat sociale problemen als zodanig geframed moeten worden en bovendien de framing verbonden is met een specifieke defini-

* Dr. Martina Althoff is als universitair hoofddocent Criminologie verbonden aan de vakgroep Strafrecht en Criminologie van de Rijksuniversiteit Groningen.

1 M. Elchardus, De dramademocratie, Houten: Uitgeverij Terra 2003.

2 E. Goffman, Frame Analysis: An Essay on the Organization of Experience, Boston: Northeastern University Press 1974. Zie ook R.M. Entman, 'Framing: Toward clarification of a fractured paradigm', Journal of Communication 1993, 4, p. 51-58. 
tie van het probleem. Als er bijvoorbeeld discussie is over drugsverslaafden in de openbare ruimte, dan is de definitie als veiligheids-, criminaliteits- of gezondheidsprobleem allereerst een kwestie van framing, waardoor aan een fenomeen verschillende betekenissen worden toegewezen.. Bij framing gaat het dus niet zozeer erom dat een fenomeen aandacht krijgt, maar om de wijze waarop het issue wordt belicht. Het onderwerp misbruik binnen de kerk heeft bijvoorbeeld tot een discussie over seksueel misbruik van minderjarigen binnen de kerk geleid. Het fenomeen had ook kunnen worden geframed door 'seksualiteit in de kerk' of (om nog en voorbeeld te geven) door 'geweld op kostscholen' te problematiseren. In het publieke (media)discours worden dus specifieke interpretaties aangeleverd en hiermee verbonden betekenissen toegewezen. Framing schept orde door de situatie, het probleem te definiëren, oorzaken en verantwoordelijkheden toe te schrijven, morele oordelen te vellen en specifieke probleemoplossingen voor te stellen.

Een analyse van mediaberichten heeft vanuit dit perspectief twee doelen: ze geeft zicht op de gebeurtenis, de verschillende frames én de hiermee verbonden betekenisgeving. Daarnaast laat een framinganalyse zien welke waarnemingen en interpretaties van de gebeurtenissen dominant zijn geworden.

Media zijn belangrijke instanties, die over criminaliteit en maatschappelijke gebeurtenissen berichten, maar ook belangrijk wat het aanleveren van betekenissen betreft. In het publieke debat mengen zich ook andere actoren, die deels via de media en deels via eigen debatten of (internet)platformen fenomenen en gebeurtenissen bespreken en er betekenissen aan toekennen. Hier vindt ook een definitiestrijd plaats over hoe de sociale wereld geïnterpreteerd moet worden. Voorbeelden zijn politici of parlementsleden die de betekenis en de consequenties voor bijvoorbeeld wetgeving en beleid bediscussiëren. De verschillende publieke discussies en debatten bij elkaar vormen het maatschappelijk discours. Mediaberichtgeving staat dus nooit los van het grote maatschappelijke debat, en een media-analyse moet die context dan ook altijd meenemen.

\section{De Keulse casus}

De eerste casus die hier zal worden besproken dient ter verduidelijking van het framingconcept. De seksuele aanrandingen en berovingen tijdens oudejaarsnacht 2015 in Keulen hebben in Duitsland en daarbuiten veel aandacht getrokken. De verhalen en beschrijvingen van die nacht leidden al gauw tot het aanwijzen van oorzaken en het toewijzen van schuld. Een centrale vraag is dan ook welke frames zich als hier dominant hebben kunnen doorzetten. De casus is ook een voorbeeld voor de vervlechting van verschillende publieke debatten. 
Carnaval van angst: de bedreiging van onze vrouwen door jonge mannelijke vluchtelingen. ${ }^{3}$

Volgens de politie en passanten verzamelen zich tijdens de oudejaarsnacht van 2015 opvallend veel jonge mannen met een allochtoon uiterlijk voor het station. ${ }^{4}$ Ze doen daar spelletjes, stoeien met elkaar en gooien vuurwerk naar elkaar. Dit gaat gepaard met alcohol- en drugsconsumptie. Rond tien uur die avond is hun aantal gegroeid tot duizend mensen. Vanwege de drukte die is ontstaan vreest de politie dat er paniek uitbreekt. Er wordt besloten de trap en het plein voor het station te laten ontruimen, waarbij wordt geprobeerd corridors naar de in- en uitgangen van het station vrij te houden. Ook in het centraal station zelf is het erg druk en hebben zich groepen jonge mannen verzameld. Getuigen spreken zelfs van chaotische toestanden. Achteraf wordt duidelijk dat juist het politiekordon en de door de politie voorgenomen ontruiming het gedrang hebben veroorzaakt, waardoor het tot de massale aanrandingen kon komen. Vrouwen berichten dat ze spitsroeden moesten lopen tussen groepen agressieve jonge mannen, waarbij hun mannelijke begeleiders in de drukte met geweld van hen werden gescheiden.

Op nieuwjaarsochtend doet de politie een eerste persbericht de deur uit. Er wordt een vergelijking gemaakt met de oudejaarsnacht van het jaar ervoor en verslag gedaan van de politie-inzet en de ontruiming. De conclusie van het persbericht is dat de situatie in de nieuwjaarsnacht over het algemeen ontspannen was. Het persbericht leidt tot enorme kritiek aan het adres van de politie, die het verwijt krijgt dat ze hiermee de gebeurtenissen in de doofpot wil stoppen. Het persbericht wordt in de daaropvolgende dagen gecorrigeerd en aangevuld met nieuwe persberichten. De storm van kritiek op de politie-inzet blijft aanhouden. In reactie hierop treedt de politiechef van Keulen op 8 januari 2016 af 'om het vertrouwen van het publiek in de politie van Keulen te herstellen'. De publieke en mediaaandacht neemt elke dag toe. De overheid roep de lokale bevolking dagelijks op om aangifte te doen. Op 5 januari zijn er uiteindelijk meer dan honderd aangiftes bij de politie gedaan. Het deelstaatparlement van Noordrijn-Westdalen (NRW) stelt een parlementaire onderzoekscommissie in. In het slotrapport, in maart 2017 gepubliceerd, komt de onderzoekscommissie tot duidelijke conclusies over de verantwoordelijkheden. Alle betrokken overheidsinstanties hebben gefaald.

Volgens de beschrijving van de onderzoekscommissie hebben zich op een bepaald tijdstip op het beschreven terrein meer dan duizend mensen verzameld, van wie de meerderheid mannen tussen de 15 en 35 jaar oud met een Noord-Afrikaans of

3 De Keulse casus heb ik eerder uitgebreid geanalyseerd en ik zal hier aan deze analyse refereren. Een minutieuze reconstructie had als doel de verschillende frames en verklaringen van de gebeurtenissen te beschrijven en analyseren. De volgende casusbespreking berust op deze analyse, waarbij de volgende tekstbouwstenen een-op-een zijn overgenomen uit het oorspronkelijk gepubliceerde artikel. M. Althoff, 'Securitisering en seksualisering van migratie: het debat over oud en nieuw in Keulen', Tijdschrift over Cultuur en Criminaliteit 2017, 3, p. 6-30.

$4 \quad$ Alle bronnen waarop de hier gepresenteerde casus berust zijn te vinden in Althoff 2017. 
Arabisch aandoenend uiterlijk. De opsporing is gericht op 286 verdachten. Tot begin september 2016 is van 152 van hen de identiteit vastgesteld: 79 asielzoekers, 12 gedoogde personen, 39 illegalen, 22 Duitsers. Meer dan 150 van de 286 verdachte personen komen uit Algerije en Marokko, 60 uit Syrië of Irak.

De rechtspsycholoog Rudolf Egg wordt in opdracht van de parlementaire onderzoekscommissie als deskundigengetuige ingezet voor de analyse van alle aangiftes. Een uitgebreide dossieranalyse van alle beschikbare aangiftes van die nacht levert het volgende beeld op: er zijn 1022 delicten gepleegd, waarvan 29,6\% uitsluitend zedendelicten, $17,2 \%$ een combinatie van zeden- en vermogensdelicten, en $46,5 \%$ van de aangiftes heeft alleen betrekking op vermogensdelicten. In totaal houdt bijna de helft $(46,8 \%)$ van alle aangiftes verband met aanranding en andere zedendelicten. Driekwart $(76,8 \%)$ van de meer dan duizend slachtoffers was vrouw, waarbij $42,7 \%$ van hen uitsluitend melding maakt van seksuele delicten. $21,9 \%$ van de vrouwelijke slachtoffers doet aangifte van een combinatie van seksuele en vermogensdelicten. Opvallend is volgens de deskundige dat de categorisering door de politie ten eerste ongelijkmatig is en vervolgens grotendeels onbegrijpelijk. Zo worden vergelijkbare delictsomschrijvingen door de slachtoffers strafrechtelijk zeer verschillend geïnterpreteerd. Vervolgens blijkt de strafrechtelijke categorisering door de politie, met dat de publieke aandacht voor de gebeurtenis in Keulen toeneemt, vanaf 4 januari duidelijk te verschuiven in de richting van een zwaardere delictsomschrijving. Bovendien worden reeds toegepaste categoriseringen gecorrigeerd. Er vindt dus deels een hercategorisering van de reeds opgenomen aangiftes plaats. Getypte aangiftes worden volgens dit rapport achteraf handmatig gecorrigeerd.

In de eerste dagen na de incidenten vindt alleen in de lokale pers een uitgebreide discussie over de politie-inzet en de aanrandingen plaats. Pas dagen daarna krijgt de gebeurtenis landelijke media-aandacht, die weken aanhoudt. Daarna volgt ook de internationale pers. Op socialemedia verschijnen sinds oudejaarsochtend en de erop volgende dagen aanhoudend verhalen van slachtoffers en getuigen die vluchtelingen als daders aanwijzen.

In de mediaberichtgeving ${ }^{5}$ over de oudejaarsnacht zijn twee thema's dominant: het vluchtelingenprobleem en de aanrandingen, waarbij het mediale discours duidelijk is in zijn framing door te spreken van de bedreiging van autochtone vrouwen door mannelijke vluchtelingen en door de islam. In de kern komen deze thema's op de meest simplificerende manier samen tot één beeld: het Duitse migratiebeleid met zijn welkomstcultuur heeft massaal allochtone jonge mannen als vluchtelingen toegelaten die de binnenlandse veiligheid en de (eigen) vrouwen

5 Een uitgebreide media-analyse van de nationale printmedia heeft o.a. Braun-Klöppel gedaan en Drüeke heeft een analyse gedaan van de berichtgeving op televisie door de Duitse omroepen ARD en ZDF. A. Braun-Klöppel, The Refugee Discourse in German Media. An analysis of the changes provoked by the events of New Year's Eve 2015 in Cologne (Master of Arts Thesis Euroculture), Göttingen/Uppsala: University of Göttingen/University of Uppsala 2016. R. Drüeke, Die TVBerichterstattung in ARD und ZDF über die Silvesternacht 2015/16 in Köln (Studie im Auftrag des Gunda-Werner-Institut für Feminismus und Geschlechterdemokratie der Heinrich BöllStiftung), Berlijn 2016. 
bedreigen. Onveiligheid is hier het dominante frame, waarbij de dreiging van vreemde moslimmannen uitgaat.

De unanieme beeldvorming over die nacht en over de verantwoordelijke daders in de media is stereotyperend en polariserend. De polarisering zit in de dader-slachtofferdichotomie: de daders - mannelijke vluchtelingen, kleurlingen, islamitisch, gevaarlijk en potentieel gewelddadig, seksueel hyperactief en niet vertrouwd met de westerse cultuur van respect voor recht, eigendom en vrouwen - staan tegenover de slachtoffers - vrouwen, jong, blank en blond, christelijk, modern en geëmancipeerd. De daders van Keulen worden gepresenteerd als homogene groep en staan symbool voor alle mannelijke vluchtelingen, en vluchtelingen worden nu geassocieerd met seksueel geweld plegende allochtone jonge mannen. Seksisme en seksueel geweld van autochtone mannen worden daarentegen nauwelijks geproblematiseerd; seksisme wordt niet als structureel probleem besproken. Ook in het politiek-parlementaire debat in de nasleep van Keulen heeft zich de constructie dat aanranding een dreiging is die in eerste instantie van (mannelijke) vluchtelingen uitgaat, hardnekkig gemanifesteerd en wordt deze in korte tijd eenop-een vertaald naar nieuw beleid. In versneld tempo worden nog in hetzelfde jaar wetswijzingen in het strafrecht en vreemdelingenrecht doorgevoerd.

Hoewel het Duitse zedenstrafrecht al langer ter discussie staat, na de nacht van Keulen ontketent zich een heftig debat, onder andere gevoerd door verschillende vrouwennetwerken en non-gouvernementele organisaties (ngo's), dat uiteindelijk tot een wetswijziging leidt. Als kernprobleem wordt gezien dat aanranding onvoldoende strafrechtelijk geregeld is. Critici stellen dat aanranding in de publieke ruimte, zoals 'aanranding boven de kleding', nauwelijks kan worden vervolgd. Half maart 2016 maakt de regering bekend dat het Duitse zedenstrafrecht wordt aangescherpt, in juli 2016 debatteert de Bondsdag over een aanzienlijke hervorming van het zedenstrafrecht, in november 2016 is de nieuwe wetgeving al van kracht. Nieuw opgenomen in het nieuwe strafrecht is seksuele intimidatie, nieuw is ook de opname van delicten waarbij gebruik wordt gemaakt van het verrassingseffect, een duidelijke link met de gebeurtenissen in Keulen.

De meest opvallende veranderingen in de wetgeving na de oudejaarsnacht vinden echter plaats in de vreemdelingenwet. $\mathrm{Na}$ de oudejaarsnacht van Keulen gaat de regering rechtstreeks de discussie aan over een hernieuwde versie dat de uitwijzing van buitenlanders met een strafdossier vergemakkelijkt en de gronden waarop asielzoekers kunnen worden uitgesloten van een vluchtelingenstatus verruimt. De wetswijziging wordt zonder grote aanpassingen op 11 maart 2016 aangenomen. Samen met de politieke discussie over de aanpassing van het zedenstrafrecht heeft dit in 2016 tot een tweede aanpassing van het verblijfsrecht geleid. Deze aanpassing volgt het voorstel dat juist ook een voorwaardelijke veroordeling voor aanranding en intimidatie (volgens het nieuwe zedenstrafrecht) als reden tot uitwijzing moet worden opgenomen in het verblijfsrecht. Juist het hierop aansluitende uitzettingsrecht heeft een hoge symboolkracht, omdat het criminaliteitsbestrijding en beheersing van migratie laat zien. Tegelijkertijd wordt migratie als veiligheidsprobleem geframed, waarbij de dreiging uitgaat van de mannelijke vluchteling. 
Het discours over de oudejaarsnacht maakt Keulen tot symbool van een maatschappelijke crisis die gekenmerkt wordt door maatschappelijke verontwaardiging. De slachtofferverhalen, de berichten van getuigen, de massaliteit van de aangiftes, maar ook de politieke consequenties voor beleid en nieuwe wetgeving zijn eenduidig in hun definitie van het probleem: de (seksuele) dreiging en het seksisme uitgaande van de vluchtelingen en hun genderbeeld.

Tijdens het begin van het publieke debat over de politie-inzet domineert het verwijt dat de politie informatie zou hebben achtergehouden ten faveure van het migratiebeleid. De reconstructie van die nacht laat echter zien dat de politie in die nacht weinig controle over de gebeurtenissen had. Deskundigen spreken in meer of mindere mate over het falen van de politie.

De problematisering van het vluchtelingenbeleid domineert hiertegenover het hele debat. Vluchtelingencrisis, een mislukt vluchtelingenbeleid, integratieproblemen en meer algemeen het thema migratie worden hier aangehaald, dienen als framing van die nacht en worden verbonden met het veiligheidsperspectief. In aansluiting op het eerder besproken framingconcept is hiermee duidelijk wat het probleem, de hiermee verbonden oorzaken en de oplossingen zijn en staat Keulen symbool voor een veiligheidsprobleem veroorzaakt door migratie.

Een tweede framing is de etnisering van seksueel geweld. Het problematiseren van seksueel geweld in de publieke ruimte is een dominant frame, maar door uitsluitend vluchtelingen hiervoor verantwoordelijk te houden en als daders aan te wijzen wordt uiteindelijk de brug gebouwd naar het problematiseren van het thema migratie. Deze specifieke en eenzijdige problematisering van het thema seksueel geweld tegen vrouwen impliceert bovendien een bagatellisering van aanrandingen in het algemeen. Een dergelijke etnisering van seksueel geweld en het polariseren van seksueel geweld dat wel daar maar niet hier gebeurt, voeden de angst voor vervreemding, omdat deze unaniem aan de vluchtelingen en hun culturele ideeën over genderrelaties toegeschreven worden.

\section{Discussie}

De framinganalyse kan laten zien hoe interpretatieve frames de reconstructie van een gebeurtenis bepalen. Het publieke debat over oud en nieuw in Keulen heeft zich ontwikkeld tot een discussie over het thema migratie en de zogenoemde vluchtelingencrisis, waarbij een problematisering van migratie vanuit een veiligheidsperspectief plaatsvindt via het thema (seksueel) gedrag van vluchtelingen en hun ideeën over genderrelaties.

De analyse heeft ook laten zien dat er verschillende andere frames mogelijk waren en in het publieke debat beschikbaar waren. De aanrandingen die nacht hadden kunnen leiden tot een discours over seksueel geweld in de publieke ruimte, een frame dat bijvoorbeeld seksuele discriminatie en intimidatie van vrouwen als focus heeft. Een ander frame had de problematisering van het werk van de politie tijdens de nieuwjaarsnacht kunnen zijn. 


\section{Beeldvorming en mediahypes over criminaliteit}

In de criminologie heeft media-analyse naast de analyse van beeldvorming door framing het doel om het ontstaan van mediahypes rondom criminaliteit en geweld te onderzoeken. Kenmerkend voor mediahypes zijn wisselwerkingen tussen mediaberichtgeving en politiek en beleid die tot veranderingen leiden en op veel maatschappelijke, culturele en politieke niveaus impact hebben.

Criminaliteit en geweld hebben een hoge nieuwswaarde voor de media, omdat het brengen van nieuws normaal gesproken het rapporteren over problematische situaties is. Voor criminaliteit betekent dit dat gebeurtenissen per definitie altijd potentieel nieuws zijn. Dit wordt versterkt doordat criminaliteit ook een containerbegrip is, waardoor criminaliteit als kader voor verschillende onderwerpen, gebeurtenissen en verhalen door de media te gebruiken is. ${ }^{6}$

Mediahypes ontstaan doordat media een aan zichzelf refererend systeem zijn. Dat betekent dat berichtgeving in de media het effect heeft dat andere media hierover (moeten) berichten. Dit kan leiden tot berichtgeving over berichtgeving, met name als het over televisie en liveprogramma's gaat. De volgende ochtend lezen we in de krant wat men in De Wereld Draait Door heeft besproken, het late journaal bericht wat er's ochtends in de Volkskrant stond. Dus media beïnvloeden zichzelf. Dit wordt versterkt doordat de politiek hierop reageert of reageren moet, wat weer tot nieuwe media-aandacht leidt. Dit zichzelf versterkende proces wordt een amplificatiespiraal genoemd, waarbij drie fasen te onderscheiden zijn. ${ }^{7}$

Media kiezen gebeurtenissen met een hoge nieuwswaarde én zoeken aansluiting bij dominante maatschappelijke debatten. Een probleem moet als zodanig geïdentificeerd en gedefinieerd worden om als nieuws te kunnen presenteren, en nieuwe gebeurtenissen krijgen pas betekenis, in termen van oude, vertrouwde problemen. ${ }^{8}$ Uitweiding en dramatisering van het probleem is de volgende fase, waarin ook veel emoties worden opgeroepen. Verbreding van de definitie van het probleem ontstaat doordat extra media-aandacht hieraan wordt geschonken en uitgebreid erover wordt bericht, en door uitweiding waarbij andere voorbeelden als vergelijkbaar worden aangehaald. De derde fase is de reactie door de overheid en andere betrokkenen, wat ook weer een nieuwsbericht waard is en opnieuw tot mediaberichten leidt. Hier ontstaat een wisselwerking tussen mediaverslaggeving, politiek en beleid of het politieke systeem. De versterkingskringloop draait nu op volle toeren: het effect van politieke debatten wordt versterkt als een beroep wordt gedaan op media-opinies en vice versa. Mediaberichten leiden tot Kamervragen, een debat in de Tweede Kamer is aanleiding voor nieuwsberichten. Samenvattend zorgt de amplificatiespiraal voor dramatisering en vergroting van het oorspronkelijke probleem.

6 M. Althoff, 'Mediaberichtgeving en het maatschappelijke discours over criminaliteit en geweld in de publieke ruimte', in: M. Althoff \& J. Nijboer (red.), Zoeklicht op geweld. Sociale conflicten in het publieke domein, Den Haag: Boom Juridische uitgevers 2010, p. 202.

7 F. Koenraadt \& C.H. Brants, 'Criminaliteit en media-hype. Een terugblik op de publieke beeldvorming rond kindermoord', Delikt en Delinkwent 1998, 6. p. 542-564. P. Vasterman, Mediahype, Amsterdam: Askant 2004, p. 41-60. 
Een algemene definitie van een mediahype levert Vasterman in zijn onderzoek: 'Een mediahype is een mediabrede, snel piekende nieuwsgolf die één gebeurtenis als startpunt heeft en die voor het grootste deel het gevolg is van zichzelf versterkende processen bij de nieuwsproductie. ${ }^{9}$ Effect van een mediahype is dus dat het lijkt alsof het criminaliteitsprobleem veel groter en erger is dan in de werkelijkheid, hoewel er één initiële gebeurtenis was die tot een nieuwsgolf heeft geleid. Een tweede effect van een mediahype is dramatisering en morele verontrusting, die weer kunnen leiden tot een morele paniek in de samenleving over een sociaal probleem of een sociale groep.

Het ontstaan van een morele paniek is geen nieuw onderwerp van criminologisch onderzoek. Pionierstudies uit de vroege jaren zeventig van de vorige eeuw zijn door de criminologen Stan Cohen en Jock Young gedaan. ${ }^{10}$ Cohen heeft bijvoorbeeld de morele paniek en de mediaberichtgeving in de jaren zestig over twee vechtende Engelse jeugdsubculturen onderzocht. De studie was baanbrekend voor de criminologie, aangezien daarin niet alleen kritisch naar het ontstaan van beelden over criminelen en over misdaad en straf is gekeken, maar ook naar de effecten van deze beeldvormig en daarmee verbonden (media)machtsstructuren. Een moral panic is volgens Cohen 'a condition, episode, person or group of persons emerges to become defined as a threat to societal values and interests: its nature is presented in a stylized and stereotypical fashion by the mass media'. ${ }^{11}$ Kenmerkende fasen zijn overdrijving, bijvoorbeeld van de ernst of grootte van het probleem, en voorspelling, bijvoorbeeld dat het probleem zich zal herhalen en symbolisering waarbij verschillende elementen als symbolische kenmerken van het bedreigende fenomeen worden gepresenteerd (zoals taal, kleding, herkomst). Het concept moral panic is volgens Cohen geen beschrijvend maar een normatief concept; het gaat immers om negatieve beeldvorming van een individu of sociale groepen, die als bedreigend voor de samenleving en de heersende moraal worden neergezet. Doel hiervan is, zo stelt Cohen, de geprivilegieerde sociale groepen en hun belangen te verdedigen en te beschermen. Het concept wordt tegenwoordig nog steeds gebruikt voor criminologische analyses van mediahypes, hoewel er ook criminologen zijn die een concept van risico- en angstdiscours als meer passend voor de tegenwoordige mediamaatschappij beschouwen en hieraan de voorkeur geven. ${ }^{12}$

\section{De Goudse casus}

De Goudse casus dient ter illustratie van een mediahype. Op het einde zal ook bediscussieerd worden in hoeverre hier sprake is van morele paniek. De casus maakt de betekenis van media-analyse zichtbaar; bovendien kunnen we hier ook

$9 \quad$ Vasterman 2004, p. 31.

10 S. Cohen, Folk Devils and Moral Panics: the Creations of Mods and Rockers, Londen: MacGibbon \& Kee 1972/2002; S. Cohen \& J. Young (red.), The Manufacture of News, Londen: Constable 1973.

11 Cohen 1972, p. 9.

12 E. Carrabine e.a., Criminology. A sociological introduction, Londen/New York: Routledge 2014, p. 423-426. 
dimensies van de hiervoor beschreven framinganalyse weer terugvinden. De reconstructie van de casus focust op de tijdelijke volgorde en de ontwikkeling van de mediahype.

Bespuugd, bedreigd en beroofd: Marokkaanse jongeren terroriseren openbaar vervoer in Gouda. ${ }^{13}$

Oosterwei is een buurt in Gouda die uit een handvol straatjes bestaat en waarvan de meeste bewoners van oorsprong Marokkaans zijn. Op woensdag 10 september 2008 maakt de vervoersmaatschappij Connexxion bekend dat ze geen bussen meer laat rijden door de wijk Oosterwei. Aanleiding is volgens Connexxion de bedreiging van een buschauffeur met een mes door een Marokkaanse jongen uit die wijk.

Op zondag 14 september 2008 kopt De Telegraaf op de voorpagina 'Chauffeurs zijn bedreigingen reljeugd beu: bus mijdt Goudse wijk', en staat in het bijbehorende artikel dat de maatregel het resultaat is van klachten van buschauffeurs die bespuugd, bedreigd en beroofd worden. In de loop van de dag komen er berichten op Radio 1, in het NOS-journaal om 16.00 uur en in RTL Nieuws om 18.00 uur. Connexxion bevestigt de maatregel en legt uit een statement te willen maken dat dit niet zo verder kan, dat er sprake is van een reeks van incidenten en de situaties heel bedreigend zijn. De burgermeester en de politie ontkennen het beeld dat Connexxion schetst: het gaat maar om één incident en bovendien zijn er geen aangiftes gedaan.

Op maandag 15 september 2008 kopt De Telegraaf 'Burgemeester bagatelliseert bus incidenten' en plaatst de uitspraak van de PVV en Geert Wilders op de voorpagina: 'Wilders: Stuur het leger naar Gouda.' De burgemeester van Gouda organiseert diezelfde middag een persconferentie. Aanwezig zijn een reeks van televisiezenders en een groot aantal journalisten. Hier wordt door de burgemeester bevestigd dat niets bekend is van een dergelijke overlast van de buslijn. Connexxion spreekt van negentien incidenten, waarvan er negen in het buurtje Oosterwei hebben plaatsgevonden.

Op dinsdag 16 september 2008 stelt de PVV stelt Kamervragen over het geweld in het openbaar vervoer in Gouda aan de minister van Justitie en die van Binnenlandse Zaken. Wilders vertelt dat hij is geïnformeerd door buschauffeurs en vraagt waarom de politie, de burgemeester en de politiek hier niets aan doen. Hij stelt dat het bovendien geen probleem van Gouda is, maar dat in heel Nederland het straatterrorisme toeneemt.

13 De reconstructie is gebaseerd op een verzameling van verschillende print- en televisieberichten uit die periode. Aanvullend wordt hier gebruikgemaakt van: I. Korthagen, 'Media aandacht maakt het verschil: invloeden van mediatisering op het beleid in Gouda', Bestuurswetenschappen 2011, 5, p. 14-31. B. Nijpels, Een probleem van tien miljoen (VPRO-documentaire, serie Medialogica van HUMAN), VPRO.nl/argos 2012, zie www.youtube.com/watch?v=bPUbTaKFebM. 
Cameraploegen lopen door de wijk en proberen jongeren te filmen en wijkbewoners te interviewen over de toestanden in Oosterwei. De sfeer in de wijk is gespannen; een cameraploeg van EenVandaag die onderweg is in de wijk wordt door jongeren aangevallen. ${ }^{14}$ Opnieuw berichten alle media over Gouda. Op donderdag 18 september 2018 rijdt de bus weer door de wijk.

Op vrijdag 19 september 2008 brengt De Telegraaf op de voorpagina foto's van jongeren op straat met de kopjes 'Dit is Gouda' en 'Reljeugd is de baas op straat'. In de volgende dagen blijven de media berichten over de casus. Er wordt gemeld dat de beroving van de buschauffeur gepleegd werd door een Marokkaan. De politie zegt niet te kunnen bevestigen dat de dader iemand van Marokkaanse afkomst is, omdat er na het politieonderzoek geen verdachte kon worden aangehouden voor de beroving.

Op dinsdag 23 september 2008 wordt de burgemeester van Gouda in De Wereld Draait Door geïnterviewd. Hij geeft aan om extra geld te willen vragen voor een plan van aanpak voor die wijk en wordt hierop zwaar aangevallen, omdat hij eerder steeds ontkende dat er iets aan de hand is en dat de gemeente nu misbruik maakt van de mediaberichtgeving. ${ }^{15}$ Op donderdag 25 september 2008 vindt een spoeddebat in de Tweede Kamer plaats. Hero Brinkman van de PVV stelt dat vele steden van Nederland worden geteisterd door een epidemie van Marokkaans geweld.

Uiteindelijk gebruikt de burgemeester van Gouda het politieke debat in de Tweede Kamer om een miljoen euro voor die wijk aan te vragen en onderbouwt het plan van aanpak door te refereren aan de beroving van een buschauffeur. Ter rechtvaardiging wijst de burgermeester op televisie in De Wereld Draait Door erop dat hij de incidenten en de beeldvorming gebruikt om extra geld af te dwingen en zijn beleid te implementeren.

Later wordt bekend dat van de negen door Connexxion genoemde incidenten er drie in Oosterwei plaatsvonden, waarbij Connexxion deze niet voldoende ernstig vond om aangifte te doen. Uiteindelijk wordt duidelijk dat de aanleiding van de media-aandacht één incident van bedreiging van een buschauffeur met een mes was, waarvoor wel aangifte is gedaan, maar dat helemaal niet in Oosterwei heeft plaatsgevonden. Later wordt ook bekend dat een lastige verkeerssituatie in die wijk de reden was om de haltes te sluiten. ${ }^{16}$

\section{Discussie}

Het wordt duidelijk dat hier sprake is van een mediahype in de nauwe zin van de definitie, waarbij één incident de aanleiding is en tot een twee weken aanhoudende publieke aandacht leidt en door de media wordt uitvergroot. In het vervolg van de berichtgeving refereren media regelmatig aan zichzelf. Dit kan, getuige de Goudse casus, leiden tot toenemende media-aandacht. Media beïnvloeden zichzelf én - zoals deze casus illustreert - worden versterkt doordat de politiek hierop 
reageert of deze opnieuw voedt. De wisselwerking tussen media, politiek en beleid leidt uiteindelijk tot beleidsmaatregelen die zijn gebaseerd op de ontstane beeldvorming.

Een volgende vraag is dan of hier ook sprake is van een morele paniek. In zijn onderzoek naar de maatschappelijke reactie op Marokkanen heeft Bouabid ${ }^{17}$ verschillende grote incidenten nader onderzocht, waaronder het Goudse busincident. De Goudse casus laat volgens dit onderzoek alle (door Stan Cohen beschreven) typische kenmerken van morele paniek zien: de overdrijving van de gebeurtenis door één incident te gebruiken om een buslijn niet meer te laten rijden en over rellen en terreur in Gouda (Oosterwei) te spreken. Bovendien wordt later bekend dat de overval niet in deze wijk heeft plaatsgevonden en dat de etniciteit van de verdachte tijdens de mediaberichtgeving nog onbekend was. De gebeurtenis in Gouda wordt middels symbolisering gekoppeld aan een grotere probleemgroep, 'de Marokkanen', die het immorele kwaad belichamen, de folk devils. De kenschetsing van het thuis van de gedefinieerde folk devils als Marokkanenwijk, als probleem-, achterstands- of overlastwijkwijk of bijvoorbeeld als no go area, en de labelling van het gedrag van de folk devils die bewoners, passanten en buschauffeurs bedreigen, bespugen of bijvoorbeeld beroven, zijn evenzo deel van deze symbolisering. Het beeld van de Marokkaanse jongeren is dan het beeld van een overlastgever en crimineel, zonder de juiste moraal van goed en kwaad, waarvoor de afkomst en cultuur verantwoordelijk worden gemaakt en als verklaring worden aangehaald; de culturele en morele ander is gecreëerd. Naast de media levert de politiek bijdragen aan de morele paniek door hierop te reageren, deze te bevestigen of nieuw beleid te stimuleren.

\section{Conclusie}

De twee hier gepresenteerde casussen illustreren de betekenis van media-analyse in de criminologie en haar relevantie in een mediamaatschappij. Mediatisering is een kenmerk van de tegenwoordige tijd en heeft veel impact op de waarnemingen van misdaad en straf en van onze werkelijkheid. Toenemende mediatisering van de samenleving betekent niet alleen toename in media-aandacht, maar ook verandering in de cultuur van mediaberichtgeving. Het begrip 'mediamaatschappij' is hier een veelgebruikte term. Was er in de oude mediacultuur nog sprake van een duidelijke scheiding tussen mediale en reële werkelijkheid en tussen realiteit en fictie, deze is verdwenen in een gedigitaliseerde en mediale cultuur. Het medialandschap is niet alleen veranderd, maar 'medialiteit' is een kenmerk van onze werkelijkheid geworden. Met andere worden, er is geen 'buiten de media' meer mogelijk.

'Above all, mediatization in the contemporary sense refers to a universe in which the meaning of ontological divisions is collapsing: divisions between fact and fiction, nature and culture, global and local, science and art, technology and humanity. (...) Mediatization (...) should be seen as a condition, or a state of being, 
attendant upon these developments and transformations but at the same time, transformative of them. ${ }^{18}$

De permanente en wederzijdse zelfreferentie van media, ook intertextualiteit of media forms ${ }^{19}$ genoemd, de actieve rol die het publiek inmiddels inneemt, bijvoorbeeld via de sociale media, maar ook het feit dat media toenemend meer zelf actoren zijn buiten de berichtgeving om, kenmerken een dergelijke gemediatiseerde (media)maatschappij, waarin criminaliteit altijd nieuwswaardig is.

18 S. Brown, Crime and Law in Media Culture, Buckingham: Open University Press 2003, p. 22.

19 Brown 2003, p. 24. 